
Periodica Polytechnica
Civil Engineering

62(1), pp. 148-161, 2018

https://doi.org/10.3311/PPci.10687

Creative Commons Attribution (i)

RESEARCH ARTICLE

\section{Effects of Structural Parameters on Seismic Behaviour of Historical Masonry Minaret}

\author{
Barış Erdil $^{1}$, Mücip Tapan ${ }^{1 *}$, İsmail Akkaya², Fuat Korkut ${ }^{1}$
}

Received 02 March 2017; Revised 19 April 2017; Accepted 12 May 2017

\begin{abstract}
The October 23, $2011\left(M_{w}=7.2\right)$ and November 9, $2011\left(M_{w}=\right.$ 5.6) earthquakes increased the damage in the minaret of Van Ulu Mosque, an important historical masonry structure built with solid bricks in Eastern Turkey, resulting in significant shear cracks. It was found that since the door and window openings are not symmetrically placed, they result in unsymmetrical stiffness distribution. The contribution of staircase and the core on stiffness is ignorable but its effect on the mass is significant. The pulpit with chamfered corner results in unsymmetrical transverse displacements. Brace wall improves the stiffness however contributes to the unsymmetrical behaviour considerably. The reason for the diagonal cracks can be attributed to the unsymmetrical brace wall and the chamfered pulpit but the effect of brace wall is more pronounced. After introducing the cracks, a new model was created and calibrated according to the results of Operational Modal Analysis. Diagonal cracks were found to be likely to develop under earthquake loading. Drifts are observed to increase significantly upon the introduction of the cracks.
\end{abstract}

\section{Keywords}

Van Ulu Mosque, Van earthquakes, operational modal analysis, seismic performance, brick masonry

\footnotetext{
${ }^{1}$ Dept. of Civil Eng., Yuzuncu Yil University, Van, Turkey

${ }^{2}$ Dept. of Geophysical Eng., Yuzuncu Yil University, Van, Turkey

*Corresponding author email: mtapan@yyu.edu.tr
}

\section{Introduction}

Van is one of the most important historical lands in Eastern Turkey. The date that human settlement was seen goes back to almost $5000 \mathrm{BC}$ and the city hosted several nations of several states. Being the capital city, the period of Urartian kingdom was the most brilliant period for Van (called as Tushpa). After that, Armenian Orontids, Persians, Byzantines, Seljuk Empire, Mongols, Kara Koyunlu Turks and Timurids held power on the city. Finally Ottomans conquered the city in mid-16th century and kept it as a separate state until the establishment of Turkish Republic [1].

All empires and states habited in this region left their notable cultural and architectural values. In order to keep and protect those values, they should be first determined, the actual state should be carefully studied and if necessary quality projects should be made to protect and transfer them to the future generations. The determination phase was done already for most of the historical structures. The actual situation and past activities related to the structure was also recorded for some structures. However no action was started after that for most of the historical structures. Since most of them faced with several wars, experienced several earthquakes and varying temperature changes, some deterioration is inevitable in terms of material and structural point of view.

Fig. 1 shows the change in Old Van City in 100-year period. The city at this region was completely lost after the wars and earthquakes and only a few religious buildings (mosques) which were also severely damaged, remained today. Van Ulu Mosque is one of the remarkable architectural examples in the Old Van City and it is one of the survived ones in the region. No marked stone was found, however, according to the material and structural properties it was stated that the mosque dates back to $12^{\text {th }}$ or $13^{\text {th }}$ century [1]. Although the mosque was collapsed, its minaret which is a tall slender tower-like structure located next to the mosque and used to inform the people about the time for pray and summon them to pray in the mosque, still standing (Fig. 1.b). Like the general construction characteristics for minarets, it has almost square base called pulpit, a cylindrical body and helicoidal staircase which are attached to 
the core inside the cylindrical body. In Fig. 1.a, a balcony and the roof is clearly seen but neither of them survived today as shown Fig. 1.b. Since the minaret is located next to the mosque it has a connection with the west wall of the mosque.
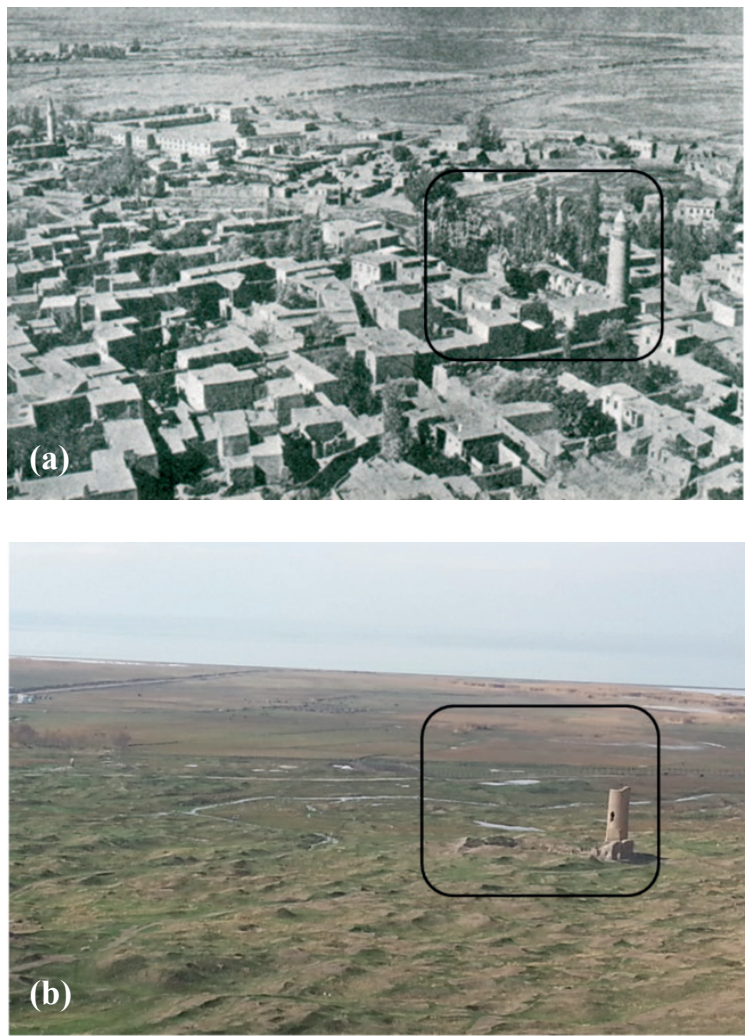

Fig. 1 The change in Old Van City and Van Ulu Mosque in 100-year period a) Old Van City and Van Ulu Mosque in 1913 [2], b) Old Van City and Van Ulu Mosque in 2013

The October 23, $2011\left(\mathrm{M}_{\mathrm{w}}=7.2\right)$ and November 9, 2011 $\left(\mathrm{M}_{\mathrm{w}}=5.6\right)$ earthquakes increased the damage in the minaret resulting in significant shear cracks and permanent deformations. Although those problems existed before, they increased after the recent earthquakes. Recalling that several minarets even built from reinforced concrete collapsed in other cities in the past earthquakes [3-5], the damaged minaret of more than 750 year old experiencing several earthquakes was not knocked down. Being in highly vulnerable state, it should be dealt with immediately with great care and preserved for future generations. To serve this need, a site survey was conducted to evaluate the damage state and determine some structural and material properties. Operational Modal Analysis was performed to find the modal information and FEM model was created and calibrated accordingly. Several models were built to understand the reason for the cracks.

\section{Main properties of the Minaret}

The minaret consists of five main parts (Fig. 2): an almost 65 $\mathrm{cm}$ thick cylindrical body (external shell) with an outer diameter of $380 \mathrm{~cm}$, a solid cylindrical core with a diameter of 100 $\mathrm{cm}$, the pulpit, the brace wall which is the part of the collapsed mosque at the east side of the minaret and helicoidal staircase connecting the body and the core. From the old pictures it was found that the cylindrical minaret was standing on a square base with a chamfer at the north-west corner called pulpit with almost $440 \mathrm{~cm}$ wide. The main material of the minaret was brick with $200 \times 100 \times 60 \mathrm{~mm}$ dimension. Mortars were used at the bed and head joints to create connection between the bricks.
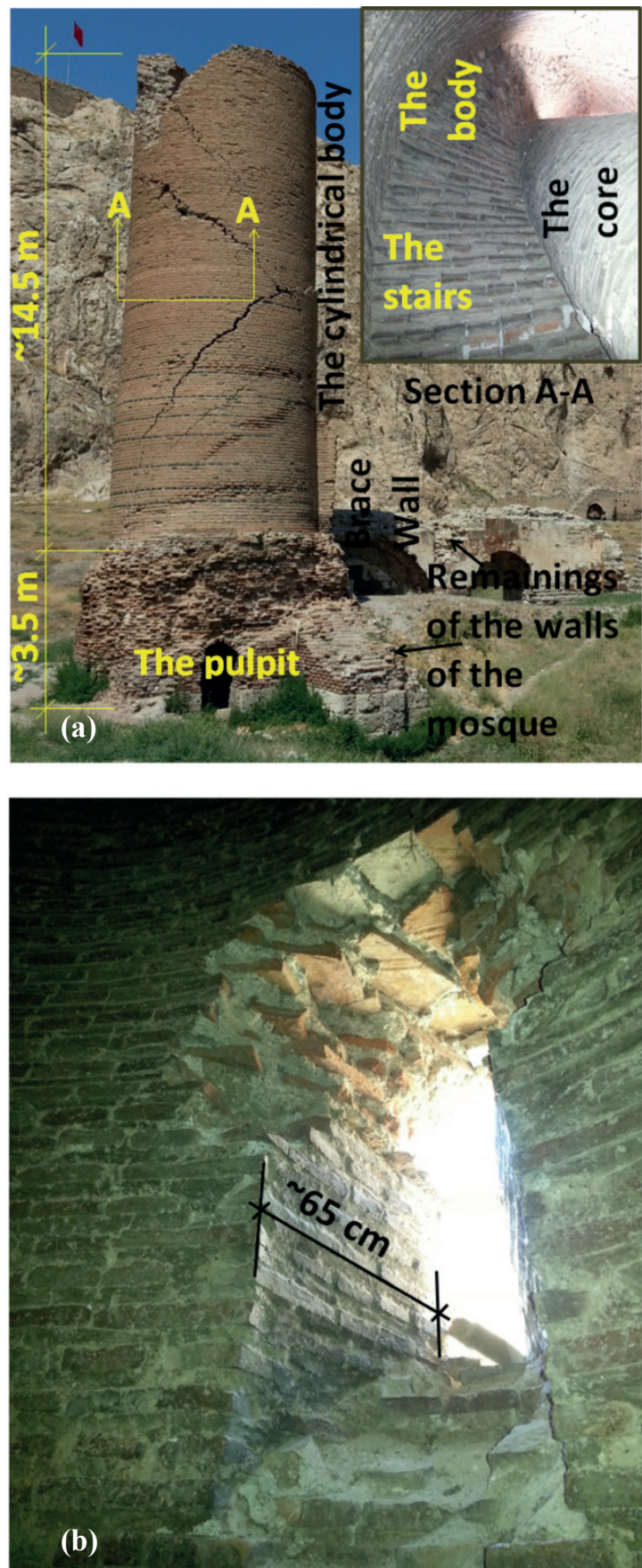

Fig. 2 a) Some basic properties and b) wall section and brick layering of the minaret

There are three openings on the external shell of the minaret in the present situation: one door opening at the pulpit, window openings at the east and north facades. Window opening at the east facade is larger than the one at the north facade. East facade of the minaret is attached to a wall segment of the mosque. The wall segment is called brace wall in this study and it has a height of $4 \mathrm{~m}$ above the pulpit. 

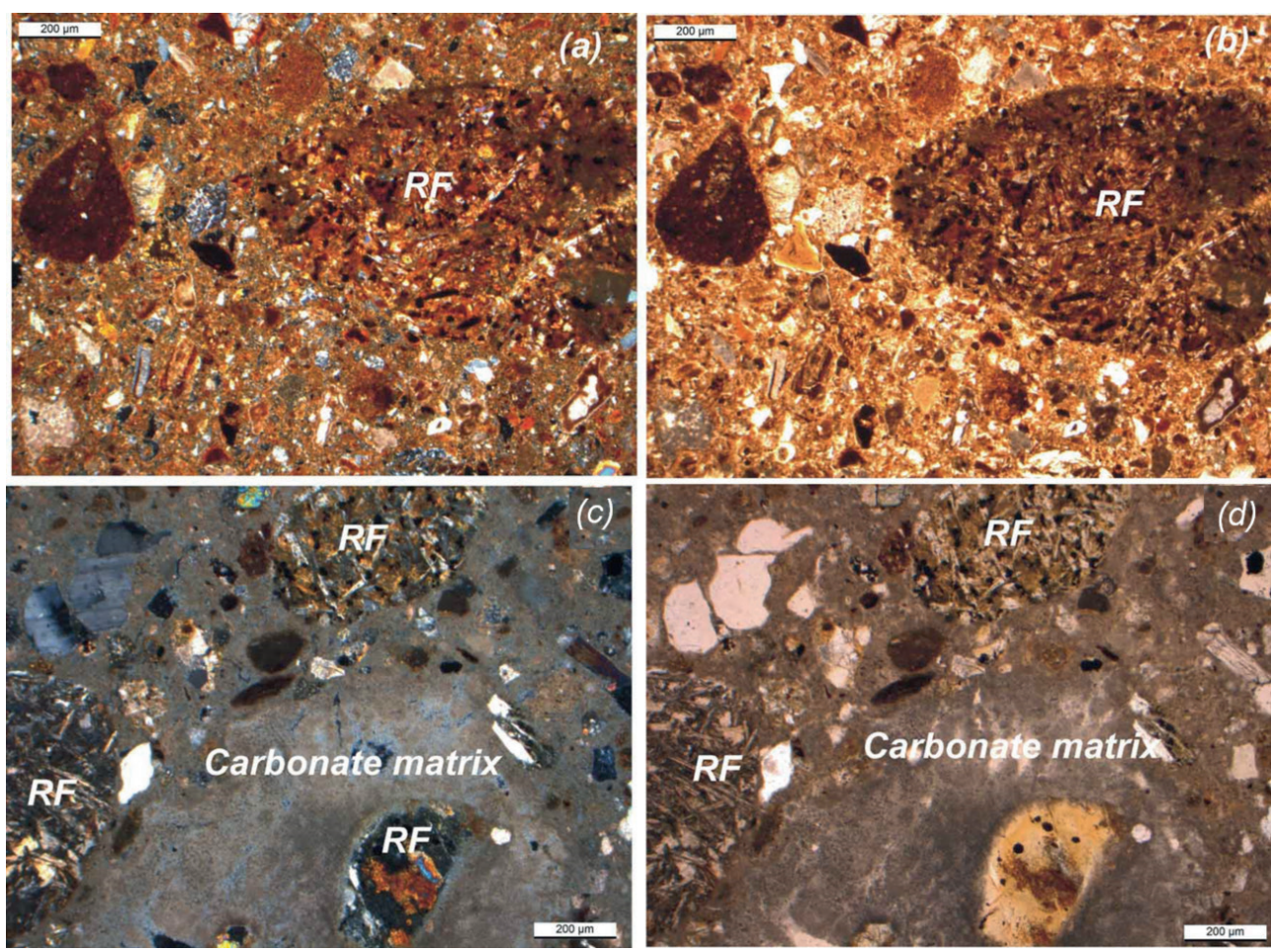

Fig. 3 Photomicrographs of the thin sections (scale $200 \mu \mathrm{m}$ ) a-b) Brick sample, c-d) Mortar sample

\subsection{Material properties}

Main material type of the structure is solid fired clay brick (shortly brick) and mortar. Brick and mortar samples of the concerned minaret were collected from the collapsed part and chemical analysis and petrographic mineral identification were performed to identify their material properties.

From the petrographic analysis of the brick samples, it was found that they have volcanic origin and the main material was ignimbrite which is common in the region. Brick samples are composed of rock particles, pumice stone, mineral crystals and volcanic glass (Fig. 3). The XRD results revealed that there are high concentrations of minerals of calcite, quartz, illite and feldspar. However, mortars have different compositions as compared to bricks and the matrix is found to consist of carbonates and is in highly heterogenic structure including volcanic, sedimentary, serpantinite, rock particles and minerals. Having different rock particles and minerals in a matrix made of carbonate indicates that the mortar is a mixture of river sand and limestone (Fig. 3). The XRD results verify that observation, since the mortar was found to be composed of densely populated gypsum and calcite and also less densely feldspar, clay and quartz are visible.

The chemical properties are summarized in Table 1. Brick samples have trachyte character according to the LeBas et. al.'s [6] total alkaline-silicate diagram and belong to the volcanic rock class having alkaline properties. Besides, the high oxide concentrations such as $\mathrm{SiO}_{2}$ and $\mathrm{Al}_{2} \mathrm{O}_{3}$, $\mathrm{LOI}$ (Loss on ignition) is also high due to the deteriorations. On the other hand, the mortar samples had high amount of $\mathrm{CaO}$ but low silica compositions. Those samples have also high LOI due to the same reason in brick samples.
Numerous studies were conducted to evaluate the physicomechanical properties as well as the deterioration mechanisms of natural building stones in the preserved historical structures [7-10]. The uniaxial compressive strength of the ignimbrite rock specimens were determined to be $28.92,15.78,12.10$ and $12.43 \mathrm{MPa}$, for four different types of ignimbrite rocks found in Van Lake region [10]. The brick samples taken from the minaret of Van Ulu Mosque were uniaxially tested and the compressive strength of the bricks was determined to be $9.88 \mathrm{MPa}$ [9].

Table 1 Results of the chemical analyses

\begin{tabular}{lcc}
\hline Property & Brick, \% & Mortar, \% \\
\hline $\mathrm{SiO}_{2}$ & 53.60 & 14.20 \\
$\mathrm{Al}_{2} \mathrm{O}_{3}$ & 13.40 & 3.06 \\
$\mathrm{CaO}$ & 9.76 & 26.49 \\
$\mathrm{Fe}_{2} \mathrm{O}_{3}$ & 8.38 & 1.82 \\
$\mathrm{MgO}$ & 6.48 & 2.08 \\
$\mathrm{~K}_{2} \mathrm{O}$ & 2.09 & 0.62 \\
$\mathrm{Na}_{2} \mathrm{O}$ & 1.94 & 0.43 \\
$\mathrm{SO}_{3}$ & 0.18 & 32.34 \\
$\mathrm{LOI}$ & 3.15 & 18.77 \\
\hline
\end{tabular}

\subsection{Damage identification}

The minaret experiences several problems such as mortar disintegration, brick loss, cracking, crushing, and partial collapse. Mortar disintegrations are mainly at the pulpit as shown in Fig. 4. The pulpit had no significant deteriorations in 1913 because it was attached to the walls of the mosque. However, after losing the walls of the mosque the pulpit became open to the environmental effects, such as freeze-thaw, wind loads 
and temperature changes and finally deteriorations took place. Although bricks are mainly in good condition, mortar layers deteriorated and were lost significantly at the exterior facade resulting in partial collapse of the bricks (Fig. 4.a). As for the interior bricks on the core facing to the door opening, although some portion of the mortar layers were lost, no disintegration was observed because there was still a considerable amount of mortar between the bricks (Fig. 4.b).
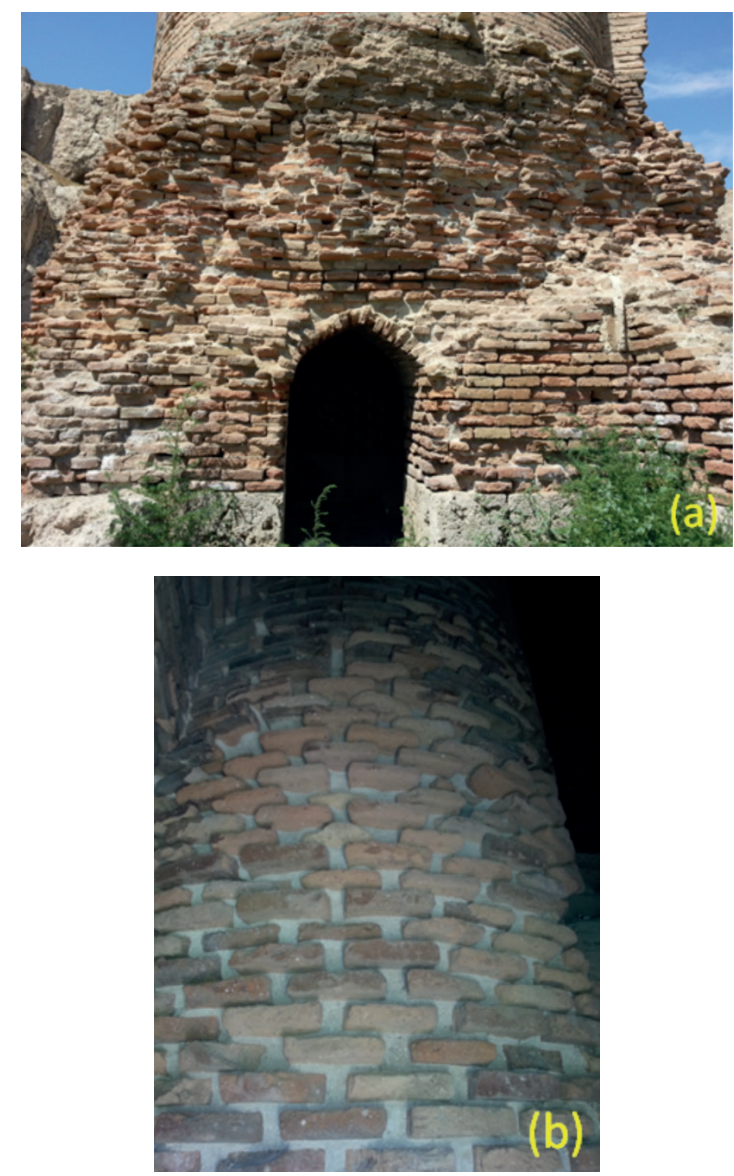

Fig. 4 a) Mortar loss and brick loss in the pulpit b) Mortar loss in the core
The October 23, $2011\left(\mathrm{M}_{\mathrm{w}}=7.2\right)$ and November 9, $2011\left(\mathrm{M}_{\mathrm{w}}\right.$ $=5.6$ ) earthquakes increased the damage resulting in significant shear cracks and permanent deformations. Present situation of the minaret is given in Fig. 5. As it is seen, all facades have wide diagonal cracks. Crack widths reach almost $10 \mathrm{~cm}$. There is a window opening at the east facade and the lintel bricks at this part were lost due to the cracking and mortar loss. Cracks are observed below the window opening and above the brace wall, and narrow diagonal cracks are also visible at the right hand side of the window. Moreover, a wide vertical crack is seen at the top. Besides, the cracks at the north facade are almost the mirror images of the south facade. The only difference is at the crack tip at the lower part which reaches to the small window opening. As for the west facade, in addition to the cracks at the upper part of the minaret projected from the south and north facades, cracks exist below the mid-height of the body.

Cracks on the exterior facade are observed to extend through the core as given in Fig. 6. Diagonal cracks on the core result in separation and out-of-plane deformations, and significant crushing are also visible on the core. Moreover, partial collapse of the staircases exists at the ground level. Although those problems existed before the earthquakes in 2011, they were observed to increase afterwards. It is seen from the post-earthquake picture that the west facade experienced partial collapse at the top level.

\subsection{Field survey and Operational Modal Analysis}

One of the important factors in earthquake dependent structural damages is the local soil conditions. For this reason, while performing an earthquake resistant design one needs the natural vibration period of soil $\left(\mathrm{T}_{\mathrm{o}}\right)$ and the soil amplification. To determine these parameters Operational Modal Analysis (shortly microtremor) technique can be used. In this method, with the vibration recordings having small amplitudes, soil behaviour during earthquakes is tried to be predicted. In urban
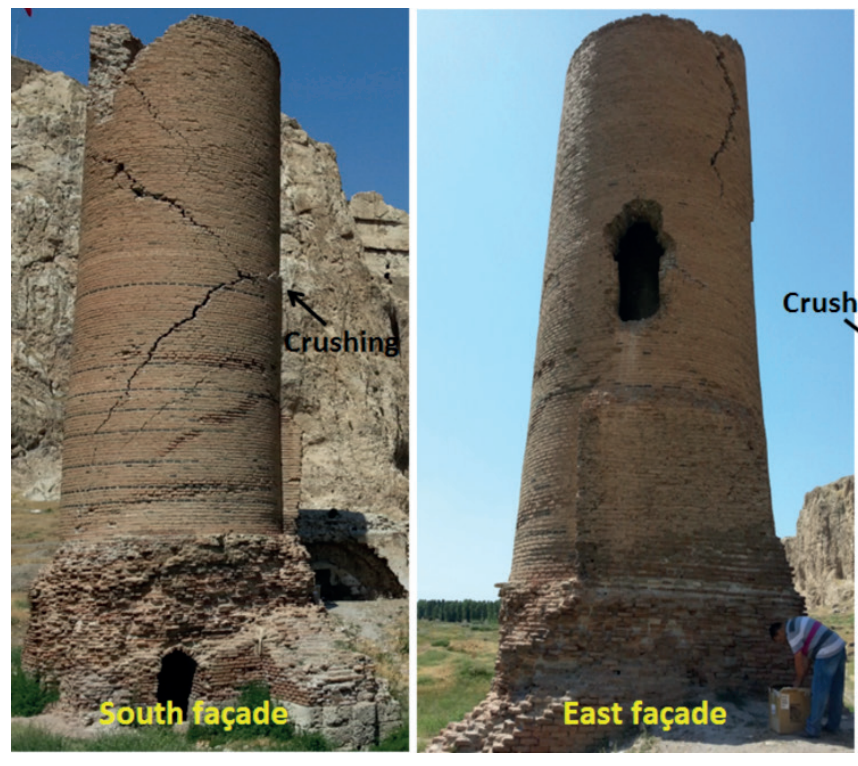

Fig. 5 Present situation of the minare
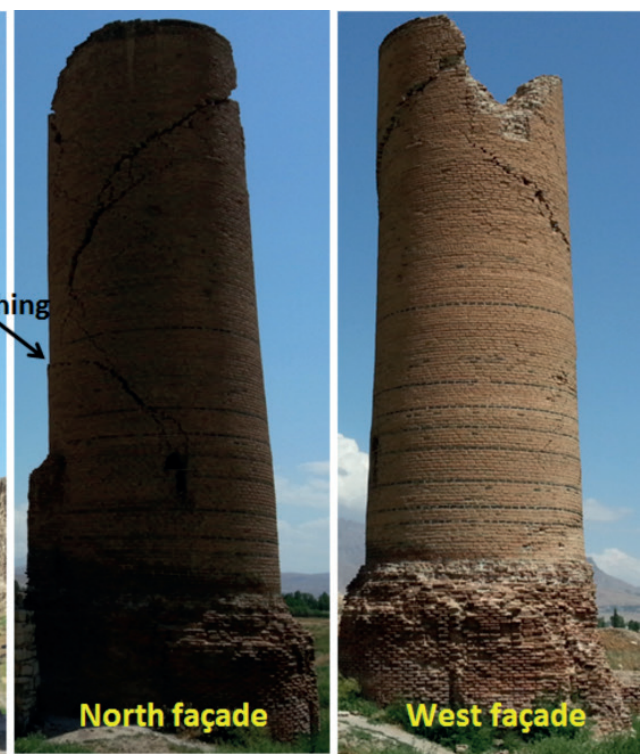

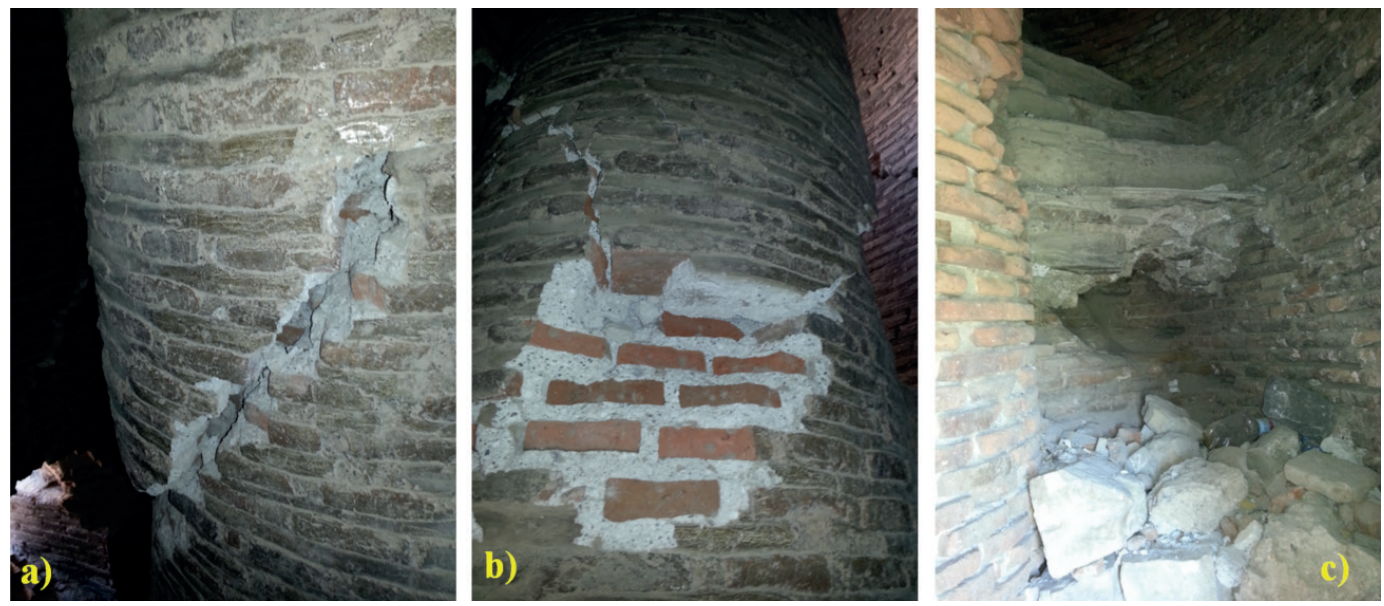

Fig. 6 a) Cracks in the core b) Crushing in the core c) Partially collapsed staircase
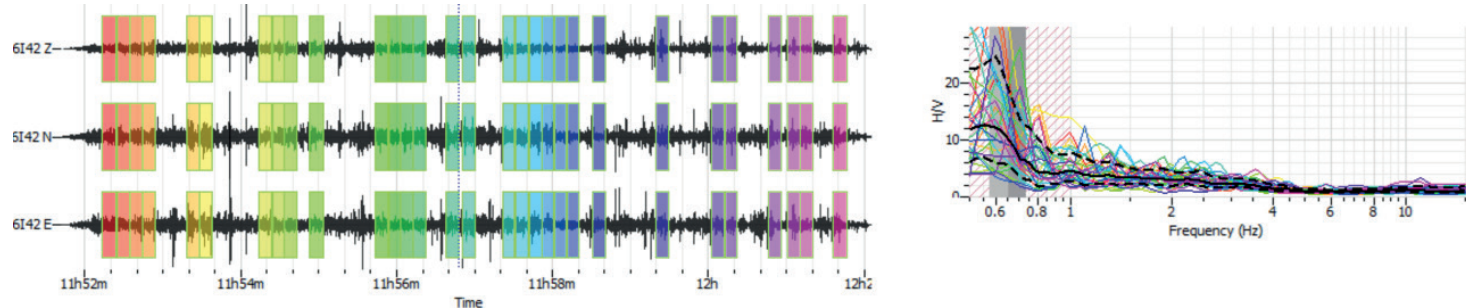

a)
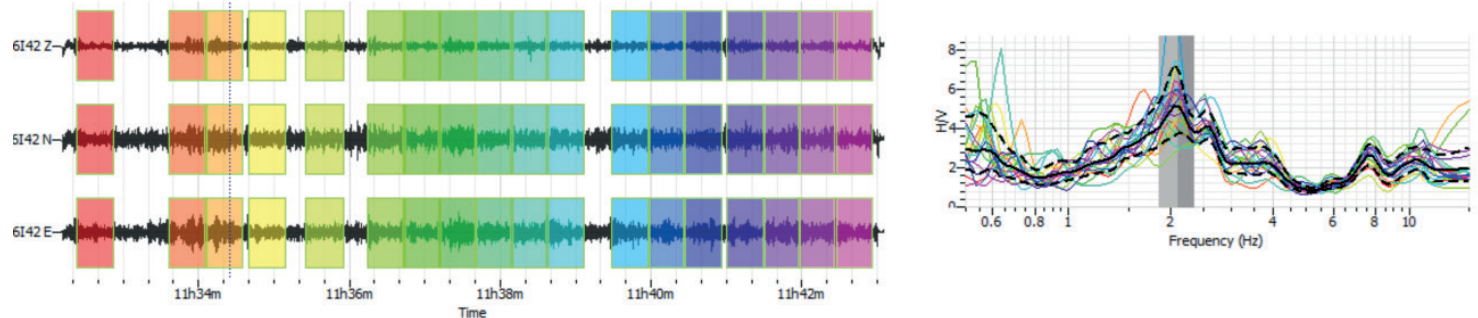

b)

Fig. 7 Microtremor data and H/V spectrums for the minaret of Van Ulu Mosque, a) Soil, b) Inside the minaret at $5.5 \mathrm{~m}$ above the ground level

areas, microtremor technique is widely used to determine the fundamental frequencies of soils [11,12].

With an altitude of 1650-1660 meters, Van Ulu Mosque is located near the Van Castle and rested on alluvium composed of loose and saturated lake sediments. The ground water level is close to the ground level. In order to determine the fundamental frequencies of the soil and also the minaret, approximately 20 min. recordings were taken from the soil and the structure. Since the minaret was damaged significantly, only at one point-5.5 m above the ground level-microtremor readings were recorded.

Microtremor recordings consist of three components (NS, EW and vertical) in time domain. According to the method proposed by Nakamura [13], natural vibration period of a soil (or a structure) can be determined from the ratio of horizontal and vertical components of a microtremor recording in spectral domain (frequency or period). This cheap and easy to apply method is known as single station method and enables fast and short time recordings.

The recordings were taken from GURALP CMG 6TD seismometer with utilizing $12 \mathrm{~V}$ batteries and the numerical data was recorded directly to a laptop. Each recording lasts approximately $20 \mathrm{~min}$. and the data had a sampling rate of 100 $\mathrm{Hz}(\mathrm{dt}=0.01 \mathrm{~s})$. The noise in each recording was firstly filtered between $0.1-10 \mathrm{~Hz}$ by using Butterworth Bandpass Filter and then windowed by 20-30 s windows and Fourier spectrums were derived accordingly. Using $40 \mathrm{~s}$ Konno-Ohmachi window, the data was flattened by applying $10 \%$ cosine tapering [14]. Finally, Geopsy software was utilized to evaluate the results (Fig. 7).

Peaks around $0.6 \mathrm{~Hz}, 2 \mathrm{~Hz}, 3 \mathrm{~Hz}, 4 \mathrm{~Hz}$ and $8 \mathrm{~Hz}$ were observed from the $\mathrm{H} / \mathrm{V}$ spectrums plotted from the microtremor recordings taken from the soil inside the mosque. The natural frequency of the soil is found to be $0.64 \mathrm{~Hz}$ and this information together with the general soil profile in the region as mentioned above reveals that the minaret was built on Z4 soil type as defined in Turkish Earthquake Resistant Code [15]. When evaluating the recordings taken from the inside of the minaret, it was realized that the natural frequency of the minaret is $2.08 \mathrm{~Hz}$ and its period is $0.48 \mathrm{~s}$ (Table 2). Since it is in highly vulnerable state no recordings were taken from the upper part of the minaret. 
Table 2 Coordinates and properties of the microtremor recordings

\begin{tabular}{lccccccc}
\hline Rec. No. & X Coord. & Y Coord. & Z Coord. & T (sn) & f (Hz) & Ampl. & Point of the recording \\
\hline 1 & 355147 & 4262879 & 1666 & 1.56 & 0.64 & 8.85 & Inside the mosque on the soil \\
2 & 355147 & 4262879 & 1672 & 0.48 & 2.08 & 4.84 & Inside the minaret at $5.5 \mathrm{~m}$ above the ground level on the staircase \\
\hline
\end{tabular}

Table 3 Structural models and the elements included in each model

\begin{tabular}{|c|c|c|c|c|c|c|c|c|}
\hline The elements & M-0-0 & M-0-1 & M-1 & M-2-0 & M-2-1 & M-3-0 & M-3-1 & M-4 \\
\hline The body & $\sqrt{ }$ & $\sqrt{ }$ & $\sqrt{ }$ & $\sqrt{ }$ & $\sqrt{ }$ & $\sqrt{ }$ & $\sqrt{ }$ & $\sqrt{ }$ \\
\hline Openings & --- & $\sqrt{ }$ & $\sqrt{ }$ & $\sqrt{ }$ & $\sqrt{ }$ & $\sqrt{ }$ & $\sqrt{ }$ & $\sqrt{ }$ \\
\hline The core & --- & --- & $\sqrt{ }$ & $\sqrt{ }$ & $\sqrt{ }$ & $\sqrt{ }$ & $\sqrt{ }$ & $\sqrt{ }$ \\
\hline The stairs & --- & --- & $\sqrt{ }$ & $\sqrt{ }$ & $\sqrt{ }$ & $\sqrt{ }$ & $\sqrt{ }$ & $\sqrt{ }$ \\
\hline The pulpit & --- & --- & --- & $\sqrt{ }$ & $\sqrt{ }$ & $\sqrt{ }$ & $\sqrt{ }$ & $\sqrt{ }$ \\
\hline The brace wall & --- & --- & --- & --- & --- & $\sqrt{ }$ & $\sqrt{ }$ & $\sqrt{ }$ \\
\hline Cracks & --- & --- & --- & --- & --- & --- & --- & $\sqrt{ }$ \\
\hline
\end{tabular}

Although it is possible to determine the frequencies of higher modes, low amplitude and dynamic effects of the soil and environmental factors made it hard to extract and if extracted the results might not be reliable. Therefore, while determining the modal information, only the dominant modes were considered as described above.

\section{Structural modelling of the Minaret \\ 3.1 Modelling strategy}

In order to understand the behaviour of the minaret of Van Ulu Mosque, 3D Finite Element Models (FEM) were built using SAP2000 v.14 software [16]. Macro-modelling approach considering the bricks and mortar layer as a homogenous continuum was utilized [17]. In this approach instead of defining the material properties of bricks and mortars separately, they were combined and assumed to behave as a homogenous material having properties of each material explicitly. Solid elements having eight nodes and being based on isoparametric formulation were used to model the minaret in 3D. Three translational degrees of freedom (dof) exist at each connected joints of solid elements whereas rotational dof are not taken into account in the analysis.

A total of 6 structural models (M-0-0, M-0-1, M-1, M-20, M-2-1 and M-3-0) shown in Table 3 were created first to understand the effect of structural parameters on cracking, then M-3-1 was used to calibrate the model according to the microtremor analysis, finally M-4 was used to obtain the seismic performance of the current state. Since the information regarding the balcony or spire is not available, they were excluded in the models. Each model is briefly described in the following paragraph.

Model M-0-0: Only the cylindrical body of the minaret is taken into account in this model without any window or door openings. This model is the reference for all the models described below.

Model M-0-1: The model considers the cylindrical body of the minaret as M-0-0 but door and window openings were introduced to determine the effect of openings on the behaviour. The cylindrical body has a thickness of $65 \mathrm{~cm}$ and its outer diameter is $380 \mathrm{~cm}$.

Model M-1: In addition to the cylindrical body in M-0-1, this model considers the core and the helicoidal staircase as well (Section C-C in Fig. 8). Diameter of the core is $100 \mathrm{~cm}$ and thickness of the stairs is $20 \mathrm{~cm}$. Those dimensions are the same throughout the height. The aim of this model is to understand the effect of staircase on the behaviour.

Model M-2-0: This model has the same properties as M-1 but additionally takes the pulpit into account. The pulpit rises up to $350 \mathrm{~cm}$ from the ground level. Since the pulpit had originally square-section with a chamfer at its north-west corner as shown from Section D-D in Figure 8, this model is created based on the original sections to understand the effect of pulpit on the behaviour.

Model M-2-1: The pulpit in the model M-2-0 is also considered in this model but the chamfer is ignored. Therefore the pulpit is assumed to be square to determine the effect of chamfer on the behaviour. The rest of the model is completely the same as M-2-0.

Model M-3-0: In addition to the elements used in the previous models, model M-3-0 considers the brace wall, which is the part of the collapsed mosque, attached to the east facade of the minaret reaching up to $400 \mathrm{~cm}$ above the pulpit as shown in Section F-F in Fig. 8. Since the brace wall was rectangular before damages and deteriorations, its original section is considered in the model. The aim of this model is to determine the effect of brace wall on the behaviour and understand whether the brace wall is the reason for the diagonal cracks or not.

Model M-3-1: This model is the same as M-3-0 except deteriorations and damage in the pulpit and the brace wall was taken into account. The model has two purposes: to determine the stiffness properties of the solid elements by calibrating the model according to the microtremor analysis and to understand the difference between the pre-damaged cases. Since significant deterioration and disintegration was seen at the pulpit, 

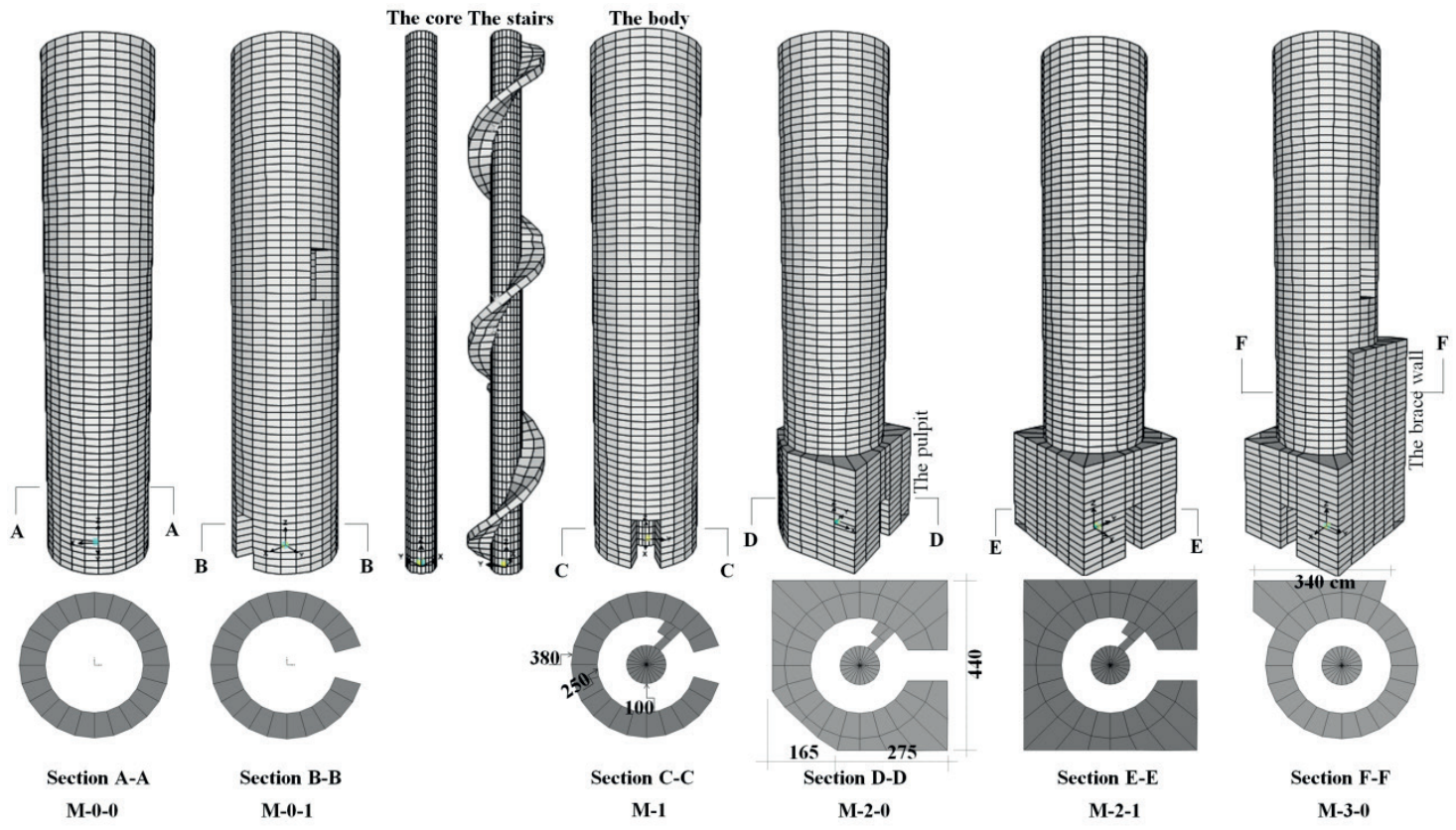

Fig. 8 3D FEM models and cross-sections of the minarets (All dimensions are in $\mathrm{cm}$ )

it was found that approximately $30 \mathrm{~cm}$ thick wall is effective over the body. Deteriorations and material loss on brick elements are approximated over the pulpit and the brace wall.

Model M-4: This model is built on Model M-3-1 and considers the cracks on the structure. It is used to understand the difference between uncracked and cracked behaviour. The cracks were modelled using nonlinear gap elements having compression-only properties. Details of the model are given in the relevant section.

\subsection{Methodology}

Unit weight of the brick elements is $18 \mathrm{kN} / \mathrm{m}^{3}$ which is typical for the brick elements $[8,18-21]$. However, stiffness is the critical and the hard one to decide because it directly influences the static and dynamic behaviour of the minaret and it depends on the interaction between bricks and mortar [22]. If all bricks and mortars have different mechanical properties, the result taken from individual elements or a part of a wall may not be representative.

Modulus of elasticity of the wall for M- $0-0, \mathrm{M}-0-1, \mathrm{M}-1$, M-2-0, M-2-1and M-3-0 was assumed to be 2.25 GPa to be consistent with the experimental results available in the literature $[20,21,23,24]$ since the aim of the first six models was to understand the each structural properties on the behavior of the minaret (Table 4).

Stiffness of the structure is directly related to the modulus of elasticity $(E)$. Therefore, in order to create a realistic model a reliable modulus of elasticity is necessary. To find $E$ to be used for the continuum in the models of M-3-1 and M-4, microtremor technique was utilized as mentioned above. From the $20 \mathrm{~min}$. recording taken inside the minaret at $5.5 \mathrm{~m}$ above the ground level from the uncracked part of the minaret, natural vibration period of the structure was calculated as $0.48 \mathrm{~s}$. This period was the target for the analysis in which a trial and error procedure was followed to find the natural vibration period of the model given in Fig. 9. The model considers the deteriorations on the bricks observed after the field survey. Deteriorations were simulated by reducing the effective area of the pulpit. Since the square pulpit lost its corners by means of brick loss, it turned out to be a cylindrical wall supporting the body at the ground level. During field survey, measurements were taken from each side of the pulpit and it was realized that an almost $30 \mathrm{~cm}$ thick cylindrical pulpit is effective over the body. Although some parts of the pulpit have greater thicknesses, due to the extensive material loss they are not reliable. Therefore it was decided to consider only the $30 \mathrm{~cm}$ as effective.

All the solid elements were assumed to have the same $E$. In the first trial, a random value $(\mathrm{E}=2.25 \mathrm{GPa})$ being consistent with the brick experiments available in the literature was assigned [20, 21, 23]. First two natural vibration periods were compared with the microtremor findings. If the periods from the analysis were less than $0.48 \mathrm{~s}$, E was reduced and the analysis was rerun. With $\mathrm{E}=2.25 \mathrm{GPa}$ it was found that $\mathrm{T}_{1}=$ $0.43 \mathrm{~s}$ and $\mathrm{T}_{2}=0.40 \mathrm{~s}$. Since periods were lower than the one found from microtremor analysis, $E$ was reduced to $2.0 \mathrm{GPa}$ and modal analysis performed again ending up $\mathrm{T}_{1}=0.46 \mathrm{~s}$ and $\mathrm{T}_{2}=0.43 \mathrm{~s}$. This showed that a slight adjustment was necessary to reach the target period of 0.48 s. Finally, decreasing $E$ to 1.8 $\mathrm{GPa}, \mathrm{T}_{1}=0.48 \mathrm{~s}$ was attained. Hence, in models M-3-1 and $\mathrm{M}-4$, solid elements were assumed to be isotropic with $\mathrm{E}=1.8$ GPa and v $=0.3$ (Table 4). 


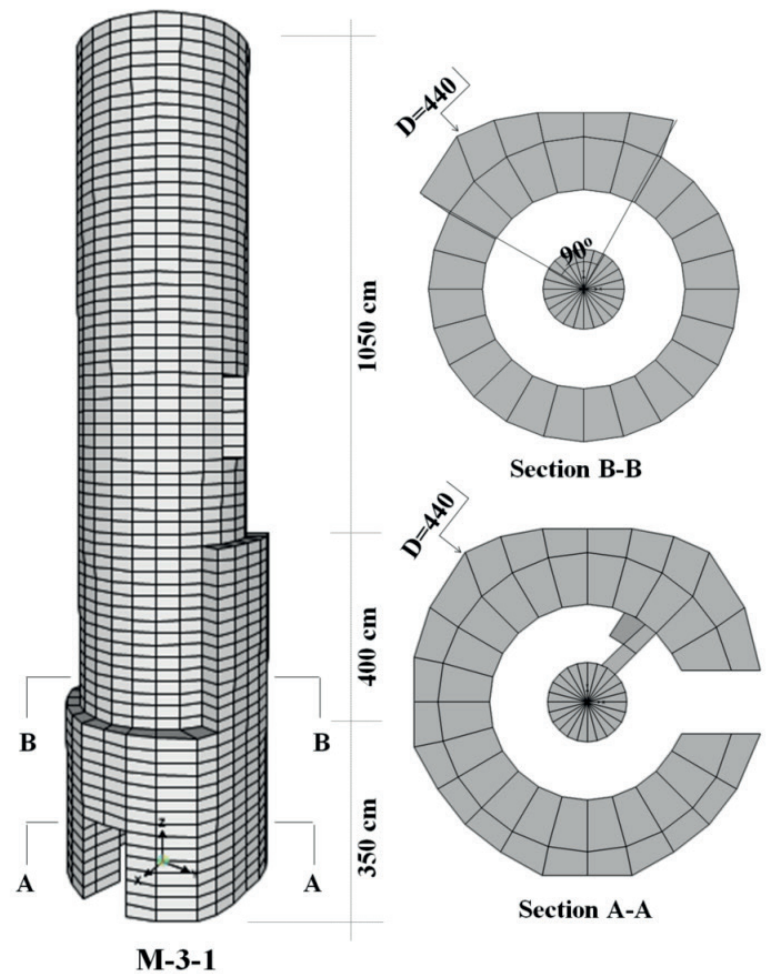

Fig. 9 3D FEM model used in calibration process (model M-3-1)

\section{Results}

\subsection{Effect of the staircase, pulpit and brace wall on behaviour of the Minaret}

In a symmetrical structure, torsion is the least possible force to develop under earthquake loading. However, if symmetry is lost, then this force becomes the most anticipated one. As a first impression, the minaret, which has a cylindrical body connected to the cylindrical core by means of helicoidal staircase, seems to have experienced severe torsional forces because of its crack pattern resembling torsional cracks. Therefore, in order to understand the influence of each element type on the response, six 3D FE models (M-0-0, M-0-1, M-1, M-20, M-2-1 and M-3-0) were created. Since the aim of those analyses was to determine the effect of each addition on the response, calibration of the modulus of elasticity according to the microtremor analysis was not performed here.

Firstly, modal analyses were performed to see the vibrational characteristics of the models. After that each model was analysed under combined gravitational and earthquake loading. For the earthquake loading, response spectrum having corner periods of $\mathrm{T}_{\mathrm{A}}=0.2 \mathrm{~s}$ and $\mathrm{T}_{\mathrm{B}}=0.9 \mathrm{~s}$ consistent with the geotechnical characteristics in the region was defined [15].
Fig. 10.a shows the change in vibration periods and Fig. 10.b reveals the change in displacements. Each curve is normalized with respect to the results of M-0-0 to better interpret the findings. As the aim of this section is to understand the effect of each structural element on the response, instead of commenting on the numbers, general response is discussed below. Raw results are also summarized in Table 5.

Vibration periods corresponding to the first $\left(\mathrm{T}_{1}\right)$ and second $\left(\mathrm{T}_{2}\right)$ mode given in Fig. 10.a reveals that the introduction of the window and door openings in $\mathrm{M}-0-1$ results in a slight increase in the periods because of the slight decrease in the stiffness. In the figure, $\mathrm{T}_{1}$ corresponds to mode shape in $\mathrm{x}$-direction whereas $T_{2}$ shows the response in y-direction. When the staircase and the core are added to the model (M-1), an increase in the stiffness and thus a reduction in the associated periods are expected, but it is not the case. It can be said that the effect of additional stiffness from staircase and the core is not significant when compared to their additional mass. Since increase in the mass is more pronounced, the model experienced higher vibration periods in $\mathrm{x}$ and $\mathrm{y}$-directions. The pulpit which confines the lower part of the minaret by reducing the adverse effect of door opening leads to a significant decrease in the vibration periods indicating that the stiffness contribution is greater than the additional mass (Model M-2-0). Ignoring the chamfer at the northwest corner of the pulpit (M-2-1) seems to have no effect on the periods. The brace wall (M-3-0) is found to result in a further reduction in $T_{2}$, since it contributes to the stiffness mainly in y-direction. Therefore, from the modal analyses, it can be summarized that the influence of pulpit on the vibration periods is more than the staircase, the openings and the brace wall since it resulted in significant reduction in the vibration periods.

Effect of each structural element on displacement response is depicted in Fig. 10.b. Displacements were calculated from the combined gravitational and earthquake loading. The general trend in the curves is similar to the ones in Fig. 10.a indicating that same kind of influences is valid for displacement response. Although the displacements in $\mathrm{x}$ and $\mathrm{y}$ directions are the same in $\mathrm{M}-0-0$, introduction of openings in $\mathrm{M}-0-1$ resulted in a different response indicating that the two openings (door opening at the south facade and a small window opening at the north facade) leads to more decrease in stiffness thus ending up with higher displacements. Displacement response in M-1 increases but the gap between $\mathrm{D}_{\mathrm{x}}$ and $\mathrm{D}_{\mathrm{y}}$ in $\mathrm{M}-0-1$ is still maintained showing that the staircase and the core have no ability to

Table 4 Input parameters of the finite element models

\begin{tabular}{lcc}
\hline Input parameter & Value for models & Value for models \\
& M-0-0, $\mathbf{M - 0 - 1}, \mathbf{M - 1}, \mathbf{M - 2 - 0}, \mathbf{M - 2 - 1 ,}$ M-3-0 & 18 \\
\hline Weight per unit volume $\mathrm{kN} / \mathrm{m} 3$ & 18 & 1.8 \\
Modulus of elasticity, GPa & 2.25 & 0.3 \\
Poisson's ratio & 0.3 & 9.88 \\
Compressive strength of brick, MPa & 9.88 & \\
\hline
\end{tabular}


Table 5 Vibration and displacement characteristics

\begin{tabular}{|c|c|c|c|c|c|c|c|c|c|}
\hline \multirow{2}{*}{ Model } & \multicolumn{3}{|c|}{ Vibration periods } & \multicolumn{3}{|c|}{ Gravity $+\mathrm{EQ}_{\mathrm{x}}$} & \multicolumn{3}{|c|}{ Gravity $+\mathbf{E Q}_{\mathrm{y}}$} \\
\hline & $T_{1}(s)$ & $T_{2}(s)$ & $\mathrm{T}_{3}(\mathbf{s})$ & $D_{x}(\mathrm{~cm})$ & $D_{y}(\mathrm{~cm})$ & $D_{y} / D_{x}(\%)$ & $D_{x}(\mathrm{~cm})$ & $D_{y}(\mathbf{c m})$ & $D_{x} / D_{y}(\%)$ \\
\hline M-0-0 & 0.48 & 0.48 & 0.11 & 8.91 & 0.00 & 0.0 & 0.00 & 8.91 & 0.0 \\
\hline M-0-1 & 0.51 & 0.49 & 0.11 & 9.74 & 0.05 & 0.5 & 0.10 & 9.00 & 1.1 \\
\hline M-1 & 0.54 & 0.52 & 0.11 & 11.18 & 0.03 & 0.3 & 0.08 & 10.33 & 0.8 \\
\hline M-2-0 & 0.42 & 0.41 & 0.10 & 6.58 & 1.65 & 25.1 & 1.66 & 6.45 & 25.7 \\
\hline M-2-1 & 0.41 & 0.41 & 0.10 & 6.51 & 0.09 & 1.4 & 0.09 & 6.38 & 1.4 \\
\hline M-3-0 & 0.41 & 0.37 & 0.10 & 5.47 & 2.86 & 52.3 & 2.82 & 5.08 & 55.5 \\
\hline
\end{tabular}

increase the symmetry level by reducing the effect of openings. The increase in the displacement response in M-1 can be attributed to the introduction of mass which contributes to the earthquake loading. Like the modal response, the pulpit resulted in significant decrease in the displacement response. Whether one of its corners is chamfered or not (M-2-0 and M-2-1), the minaret experienced same displacements in both directions indicating that the adverse effect of the openings vanished. Brace wall seems to reduce the displacement response by providing additional stiffness. However, this addition is not symmetrical and results in a different response. The difference is observed to be less than the one in M-0-1 and M-1. As a result it can be said that openings results in a higher displacement response whereas pulpit reduces the response significantly.

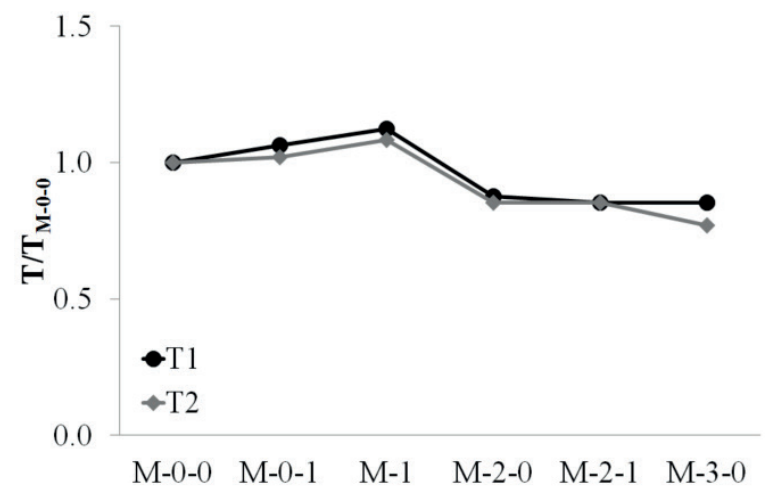

(a)

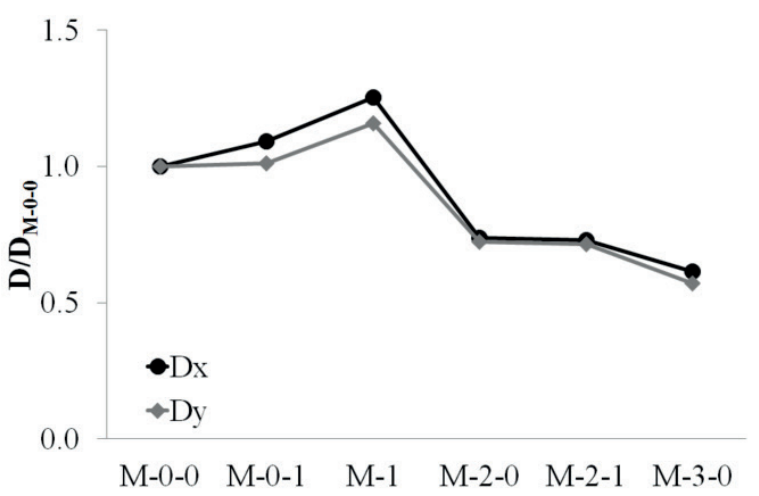

(b)

Fig. 10 a) Vibration periods in first two modes, b) Displacements under combined loading

The displacement response under combined gravitational and earthquake loading is given in Fig. 11. Because of the unsymmetrical condition of the structure, the earthquake in $\mathrm{x}$-direction may result in displacement not only in $\mathrm{x}$-direction but also in $y$-direction. Therefore, in the figure the response with the direction of a given earthquake is represented by both $\mathrm{x}$ and $\mathrm{y}$ displacements to determine the possibility of torsion in each model. Although there exists a slight difference in their stiffness in each direction, M-0-1, M-1 and M-2-1 have displacements consistent with the earthquake directions indicating that those models can be regarded as symmetric. However, M-2-0 and M-3-0 has different displacement response compared to the other models. Since the structural system in these models was not symmetric they experienced displacements in transverse direction also. This behaviour can be regarded as a sign of torsion and it is more pronounced in the model with brace wall.

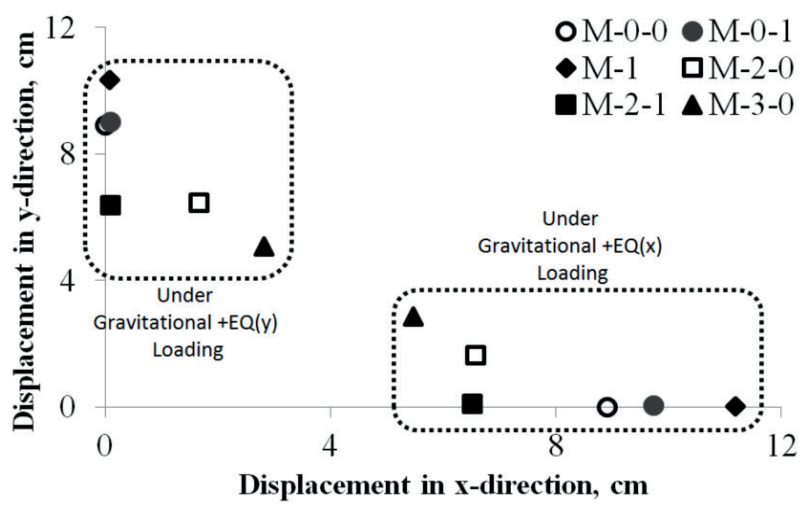

Fig. 11 Displacement in $\mathrm{x}$ and $\mathrm{y}$ directions under combined loading

Shear stress distribution (SSD) in $\mathrm{x}$ and $\mathrm{y}$ directions under combined gravitational and earthquake loading is shown in Fig. 12. From the distribution in $\mathrm{x}$-direction it is seen that, introducing window openings results in a localized shear stress around the opening in all models except M-0-0. The pulpit in M-2-0 and M-2-1 seems to relieve the stresses at the lower part of the minaret but shear stress at the top of the pulpit increased due to the sudden change in the cross-section. All the SSD are almost symmetric except M-3-0. Since the brace wall is introduced in this model, SSD changes significantly. A flow from the pulpit to the brace wall up to the window opening is visible. SSD is found to follow the staircases and stresses started to accumulate the points where the cross-section changes significantly. As for the $\mathrm{y}$-direction, it is seen that for the cylindrical body in M-00 , shear stress distribution changes gradually from top to the bottom and it is symmetric around $\mathrm{x}$-axis. However, with the 
introduction of openings in M-0-1 there exist two separate distributions around each opening. Staircase and the core slightly affect the distribution but pulpit reduces the stress in the lower part significantly. A slight unsymmetrical distribution can be seen in M-2-0 since it has a chamfered pulpit. When the chamfer is ignored the distribution again turns out to be almost symmetrical. A more pronounced and unsymmetrical distribution is seen from M-3-0. It is observed that shear stresses concentrate above the window at east facade and at the connection between pulpit and the brace wall. SSD in X-direction for M-3-0 reveals that diagonal cracks from the window to the pulpit and from the window to the above are highly possible. As a conclusion, SSD in M-3-0 is found to be consistent with the cracks on the minaret shown in Fig. 4 and it can be said that brace wall may be the cause for the diagonal cracks.

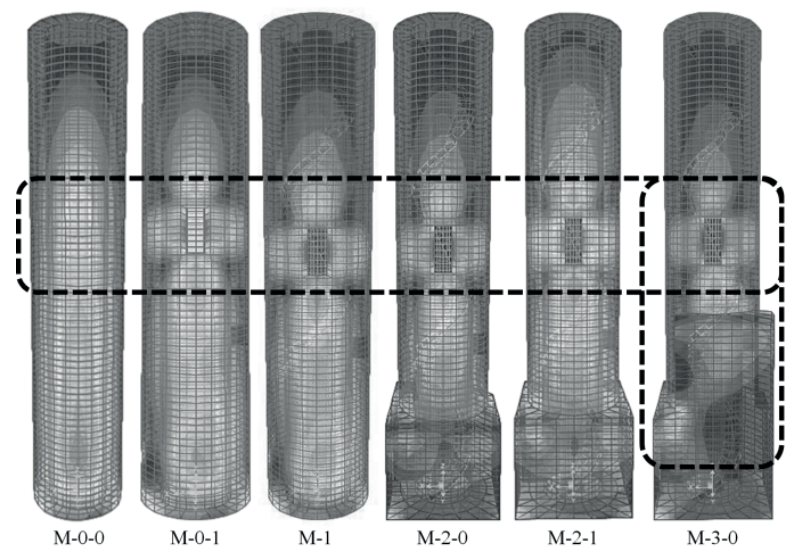

a) $x$-direction

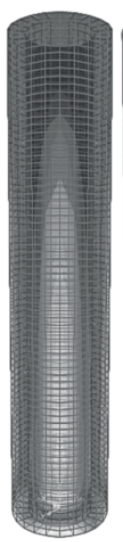

M-0-0
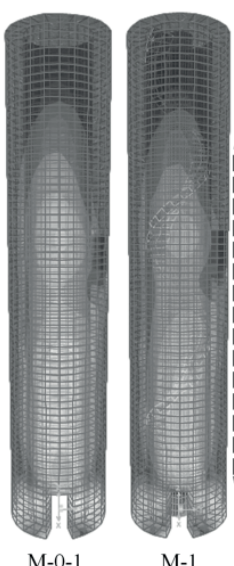

-1

b) y-direction

Fig. 12 Shear stress distribution under combined gravitational and earthquake loading

Fig. 13 depicts the change in maximum shear stress developed in each model. It is seen from the figure that maximum shear stress increases from M-0-0 to M-3-0 indicating that each change in the model influence the shear stress. Maximum shear stress increases with openings, staircase and the core but reduces with the pulpits. However, it increases dramatically with the brace wall. Change in maximum shear stress in y-direction is more pronounced indicating that shear cracks are more likely to develop in this direction. Therefore, it can be said that brace wall, opening, staircase and the core may be responsible for the diagonal shear cracks since they increase the maximum shear stress but pulpits relieve the stresses slightly.

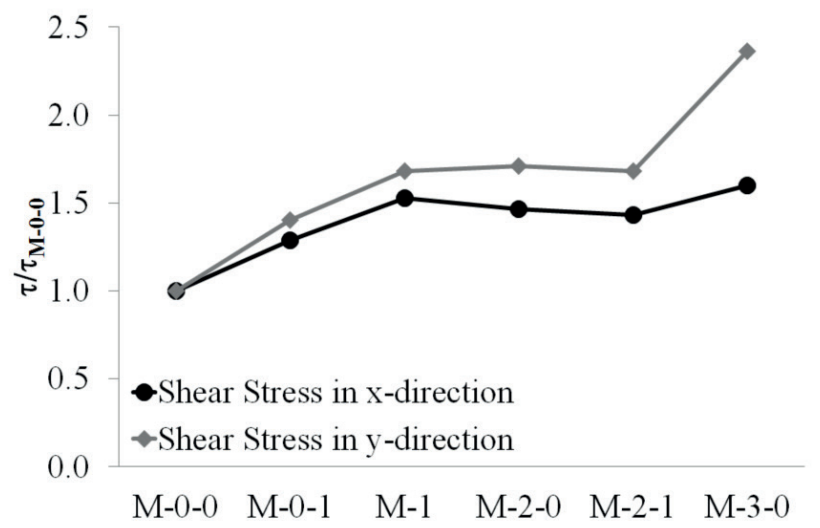

Fig. 13 Change in maximum shear stress

\subsection{Current state and the possible failure mechanisms}

The minaret experienced several cracks with almost $10 \mathrm{~cm}$ width indicating a significant separation as mentioned in the previous sections. The main reason for the cracks is believed to be the earthquake shaking, because several great earthquakes occurred in the region in the past. The last earthquakes were on October 23, 2011 with $\mathrm{M}_{\mathrm{w}}=7.2$ and November 9, 2011 with $\mathrm{M}_{\mathrm{w}}=5.6$ [25]. Those earthquakes increased the existing damage but did not lead to total collapse.

In order to create a model representing the current state of the structure, existing cracks should be introduced. Since those cracks are wide enough, non-linear gap elements were used to represent the behaviour at the cracked locations. Tensile resistance of the gap element is assumed to be zero due to the lost connection between the elements and it only carries compressive loads. It was assumed that gap elements behave only in the first principal direction (direction 1) since the main separation is in that direction. The effective stiffness to be used in linear analysis was taken as zero. It was found from the field investigation that widths of cracks vary between 2 and $10 \mathrm{~cm}$. Therefore to be consistent with the existing cracks, 2, 4, 7 and $10 \mathrm{~cm}$ gaps were defined and assigned to the relevant locations. The model M-4 and the structure are given in Fig. 14, comparatively. As it is seen, almost all of the cracks were introduced in the model.

After defining the cracks, static and dynamic analyses were performed to understand the behaviour of the current state. From the modal analysis it was found that the stiffness in $\mathrm{x}$-direction reduced significantly resulting in higher natural vibration periods as shown in Table 6 . With the reduction in stiffness, roof displacements increased $116 \%$ in $\mathrm{x}$-direction but only $50 \%$ in y-direction. No shear stress predictions were made, since the structure had already cracked. 

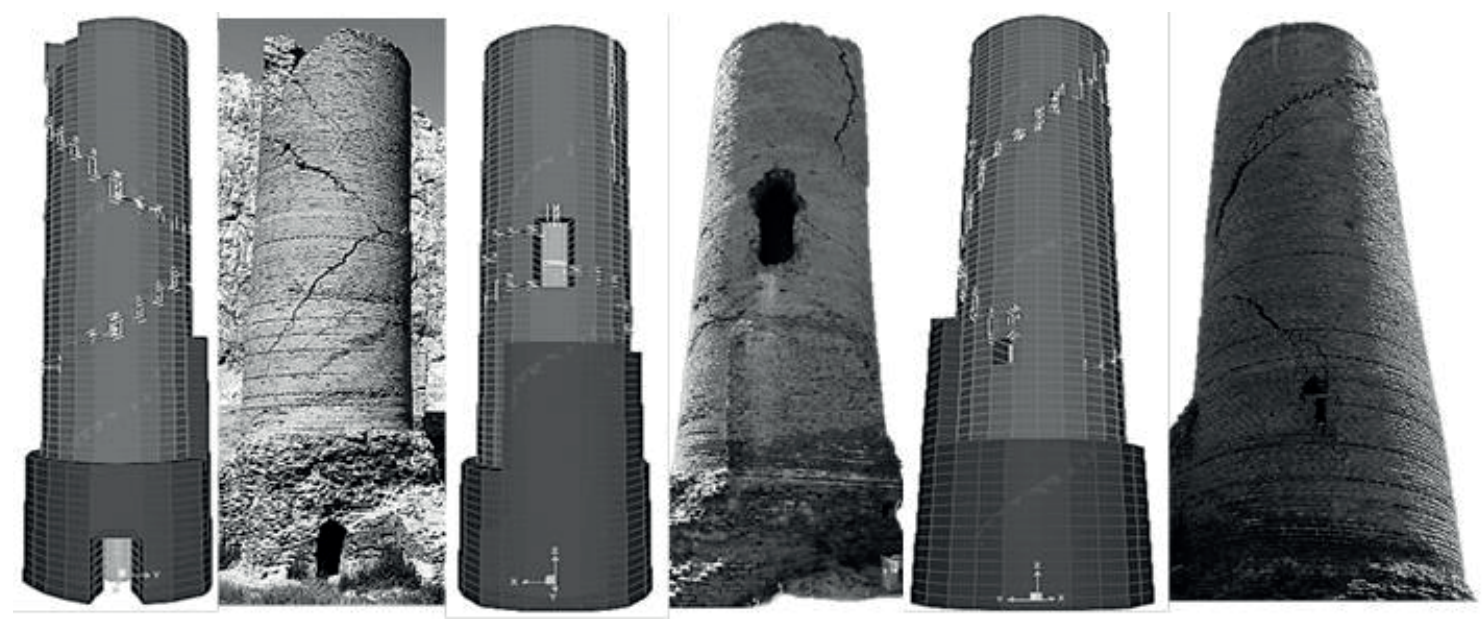

Fig. 14 Comparative view of the model M-4 and the structure

Table 6 Vibration and displacement characteristics of the current state

\begin{tabular}{|c|c|c|c|c|c|}
\hline \multirow{2}{*}{ Model } & \multicolumn{3}{|c|}{ Vibration periods } & \multirow{2}{*}{$\begin{array}{c}\text { Gravity+EQ } \\
D_{x}, \mathrm{~cm}\end{array}$} & \multirow{2}{*}{$\begin{array}{c}\text { Gravity }+E Q_{y} \\
D_{y}, \mathbf{c m}\end{array}$} \\
\hline & $\mathbf{T}_{1}, \mathbf{s}$ & $\mathbf{T}_{2}, \mathbf{s}$ & $\mathbf{T}_{3}, \mathbf{s}$ & & \\
\hline M-3-1 & 0.48 & 0.45 & 0.11 & 9.0 & 8.0 \\
\hline M-4 & $0.70[46 \%]^{*}$ & $0.53[18 \%]$ & $0.20[82 \%]$ & $19.2[116 \%]$ & $12.0[50 \%]$ \\
\hline
\end{tabular}

*Percentages in the brackets show the change with respect to M-3-1

The main problem of the structure is the stability associated with the drifts. According to in-plane tests on masonry walls composed of solid fired clay brick with mortar, diagonal cracking was stated to develop at approximately $0.1 \%$ drift, maximum drift was found to be almost $0.25 \%$ and ultimate drift was observed to be at $0.47 \%$ [24]. Since the materials used in those tests had similar characteristics as in this study, same limits are assumed to apply in the concerned minaret. Fig. 15 gives drifts of the three models (M-3-0, M-3-1 and M-4) under combined gravitational and earthquake loading together with the drift limits. M-3-0 represents the as built case, M-3-1 stands for the deteriorated but uncracked case and M-4 simulates the cracked condition. In general, drifts in $\mathrm{x}$-direction are higher than the ones in y-direction because of the unsymmetrical stiffness distribution. From Fig. 15 it is seen that M-3-0 has drifts almost equal to the maximum resistance limit state indicating that diagonal cracks are inevitable under earthquake loading. With deteriorations and material loss on the pulpit and the brace wall, stiffness degradation leading to higher drifts is possible. Drifts in M-3-1 are beyond the ones found from M-3-0 and they are around ultimate resistance limit state showing that significant damage is possible. Since the current state of the minaret reveals the significant damage, limit states given by Javed [24] seems reasonable. Although drifts in M-3-1 are almost equal to the ultimate resistance limit state, they are far beyond this level and indicate a much more dangerous situation in M-4. Drifts in $\mathrm{x}$-direction increase considerably upon cracking. It should be reminded that those values are just an estimate and do not reflect the real behaviour because of the difficulty in modelling such a highly vulnerable structure. However the results can be interpreted as a clue about the behaviour to be expected in the future incase no strengthening is applied. Although the structure survived in 2011 Van Earthquakes it may not have sufficient resistance for the next one.

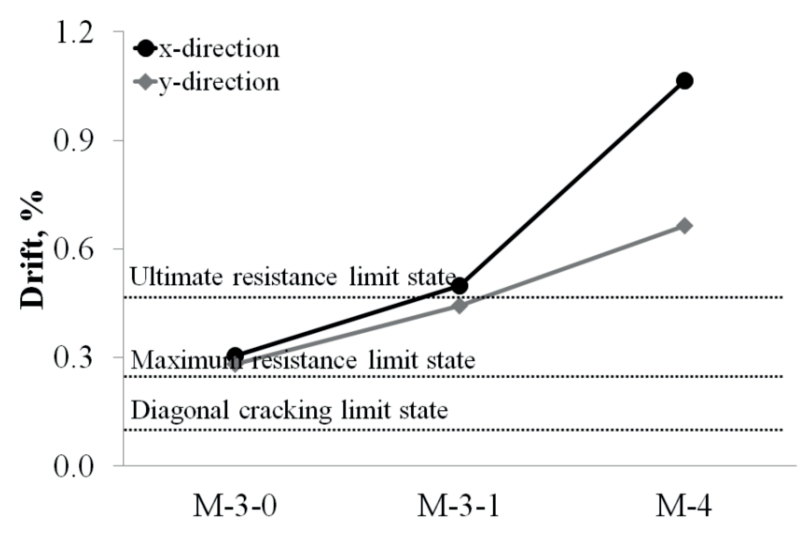

Fig. 15 Change in drifts

\section{Discussion}

Analysing a vulnerable historical masonry structure is not an easy task. The work becomes much harder when structural properties are missing and also the structure has cracks. Muvafik [9] performed linear transient seismic analysis on the same minaret considering the strong motion records from Van earthquake. Using solid elements in the model the author divided the minaret into four parts and at each part used different materials based on the material testing. After the analysis, higher stresses were observed at the transitional segments of the minaret and extra stresses were obtained at the window and door openings. Tensile stresses were found to be greater than the tensile strength and it was concluded that those stresses might be the reason for the existing cracks. However, the brace wall was not included in the model, no information was given 

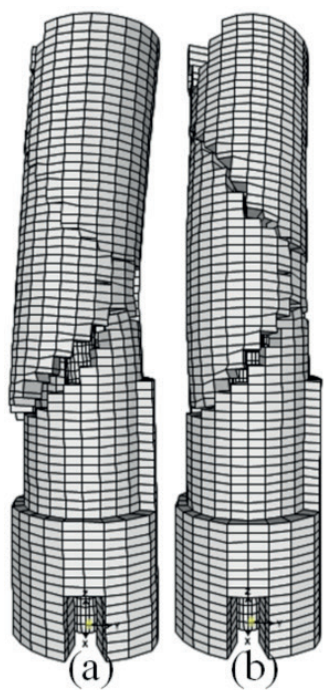

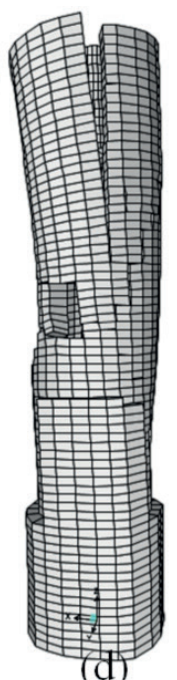

(d)

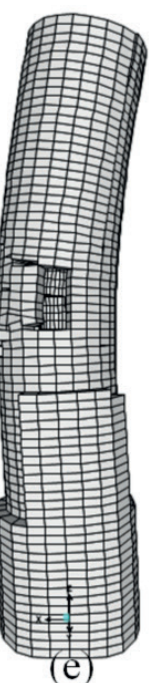

(e)

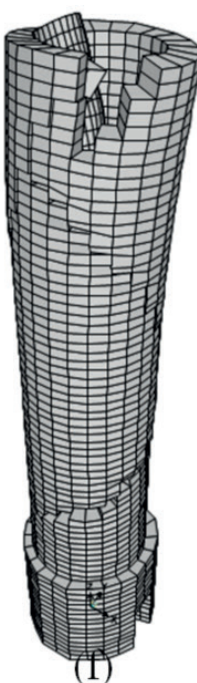

(1)

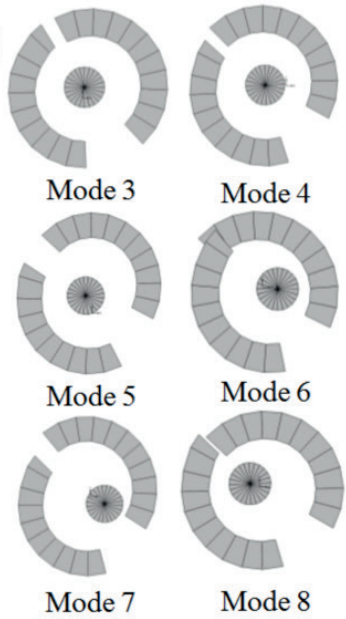

(g)

Fig. 16 Possible failure mechanisms and mode shapes of the minaret

about the cracks since they existed before the 2011 earthquakes and no conclusions were drawn about the diagonal cracks above the window opening at the north facade.

This paper aimed to find answers to the abovementioned aspects. By visual inspection at the site survey, inclined wide cracks at almost all facades of the body were observed and they were attributed to the torsional effects. Going inside the minaret and climbing upper parts it was realized that cracks also existed at the stairs and the core. The degree of the vulnerability was clear with those cracks. Although the minaret has a cylindrical body and a symmetrical plan, torsion should be the least anticipated force. In order to verify the visual inspection, several structural models including different structural parameters were created and analysed. It was found that a brace wall which was a part of the collapsed mosque was attached to the minaret and that part provided stiffness to the body and resulted in unsymmetrical stiffness distribution. After defining the problem in the minaret, it was remodelled considering the existing deteriorations and cracks to understand the behaviour under future seismic events.

Fig. 16 depicts the possible failure mechanisms of the minaret. Since the cracks are wide and cause significant separation, they endanger the whole structure and have ability to cause total collapse. Cracks divided the upper part of the minaret into several pieces and ended up little or no interaction between those pieces. There exist six possible failure mechanisms as shown in the figure:

a) upper structure may be separated from the lower stiff structure due to the cracks below the east window extending through the lower part,

b) upper structure may be divided into two separate parts and collapse accordingly,

c) the cracks from east window to the top of the west facade may cause the upper portion to collapse,

d) the body may be teared up due to the vertical cracks at the top,

e) significant cracks at the window opening may cause upper part to collapse partially and f) the core and the staircase may behave separately forcing the body to displace out-of-plane.

In Fig. 16, mode shapes of the structure are also shown from the top view to see the degree of separation and difference in the behaviour between the body and the core. Since the body has diagonal and vertical cracks, each part of the body has different response resulting either closure or opening of the cracks. It is seen from all the possible failure mechanisms and mode shapes that the structure has instability issue and significant drifts are likely to result in total collapse. Those possible failure mechanisms should be kept in mind while proposing a strengthening method. On the contrary to the upper part of the structure, no noticeable cracks or failure is expected at the pulpit and the brace wall since the elements at these locations still hold the integrity and have sufficient stiffness.

\section{Conclusions}

The minaret of Van Ulu Mosque survived after several earthquakes in its more than 750 years lifetime. Although survived, it experienced significant damage and lost its upper part together with the balcony. The damage and the cracks were observed to increase after the 2011 Van earthquakes. The cracks were almost $10 \mathrm{~cm}$ wide resulting in a considerable instability.

In order to understand the reason for the diagonal cracks, six 3D FE models were created first. It was found that since the door and window openings are not symmetrically placed, they result in unsymmetrical stiffness distribution leading to unsymmetrical vibration periods and displacement responses. The contribution of staircase and the core on stiffness is insignificant but their effect on the mass is considerable.

The pulpit increases the stiffness significantly. Vibration periods and the displacement response are improved. Although vibrational periods and displacements consistent with the earthquake directions are almost the same for the square pulpit and the square pulpit with a chamfered corner, displacements in the transverse direction are totally different. In other words, 
the pulpit with chamfered corner experiences transverse displacements which is the sign of torsional behaviour.

Brace wall improves the stiffness resulting in a further decrease in periods and displacement response. However, since it is located only at east facade, the behaviour is different in $\mathrm{x}$ and $y$ directions indicating the increase in the torsional behaviour. The same observation is also valid in shear stress distribution. The distribution is consistent with the diagonal cracks on the cylindrical body. Based on the analyses results, the reason for the diagonal cracks can be attributed to the unsymmetrical brace wall and the chamfered pulpit but the effect of brace wall is more pronounced.

Operational Modal Analysis was performed to determine the natural vibration periods of the structure and the soil from ambient vibration recordings. After that the soil was found to conform to the Z4 soil type (the weakest soil type) defined in TEC2007 [15] and first vibration period of the minaret was calculated as $0.48 \mathrm{~s}$. The FE model was calibrated according to this period and modulus of elasticity of the continuum is determined as $1.8 \mathrm{GPa}$ which is consistent with the experimental results available in the literature.

After introducing the deteriorations a new model was created and analysed. It was found that diagonal cracks were likely to develop under earthquake loading since the drifts were beyond the maximum resistance limit state. Then a new model with all of the cracks defined on the structure was built and analysed. Results revealed that the structure may experience drifts far beyond the ultimate resistance limit state and it is possible to see a failure in $\mathrm{x}$ direction where diagonal cracks are significant.

Although the structure survived in 2011 Van Earthquakes it may not have sufficient resistance for the next one. It is recommended that the structure should be handled immediately because it is on the verge of total collapse. The structural condition should be improved such that the signs of earthquake damage are still visible to remind people significance of the earthquake. Besides it should be preserved to respect its strength since it survived in the earthquakes in 2011 even though several reinforced concrete buildings collapsed in the region.

\section{References}

[1] GoV 2016. Governorship of Van, http://www.van.gov.tr/default_B0.aspx?content $=1043$

[2] Bachmann, W. "Kirchen und moscheen in Armenien und Kurdistan". pp. 69-74. J. C. Hinrichs, Leipzig: 1913.

[3] Sezen, H., Acar, R., Dogangun, A., \& Livaoglu, R. "Dynamic analysis and seismic performance of reinforced concrete minarets". Engineering Structures, 30(8), pp. 2253-2264. 2008. https://doi.org/10.1016/j.engstruct.2007.11.005

[4] Dogangun, A., Acar, R., Sezen, H., \& Livaoglu, R. "Investigation of dynamic response of masonry minaret structures". Bulletin of Earthquake Engineering, 6(3), pp. 505-517. 2008. https://doi.org/10.1007/s10518008-9066-5
[5] Çaktı, E, Oliveira, C. S., Lemos, J. V., Saygılı, Ö., Görk, S., \& Zengin, E. "Earthquake behaviour of historical minarets in Istanbul". In: 4th ECCOMAS Thematic Conference on Computational Methods in Structural Dynamics and Earthquake Engineering, Kos Island, Greece, Jun. 12-14. 2013.

[6] Le Bas, M. J., Le Maitre, R. W., Streckeisen, A., \& Zanettin, B. “A chemical classification of volcanic rocks based on the total alkali-silica diagram". Journal of Petrology, 27(3), pp. 745-750. 1986. https://doi. org/10.1093/petrology/27.3.745

[7] Topal, T., \& Doyuran, V. "Engineering geological properties and durability assessment of the Cappadocia tuff". Engineering Geology, 47(12), pp. 175-187. 1987. https://doi.org/10.1016/S0013-7952(97)00017-3

[8] Şimşek, O., \& Erdal, M. "Investigation of some mechanical and physical properties of the Ahlat stone (Ignimbrite)". Gazi University Journal of Science, 17(4), pp. 71-78. 2004. http://gujs.gazi.edu.tr/article/ view/1060000425/1060000222

[9] Muvafik, M. "Field investigation and seismic analysis of a historical brick masonry minaret damaged during the Van Earthquakes in 2011". Earthquakes and Structures, 6(5), pp. 457-472. 2014. https://doi. org/10.12989/eas.2014.6.5.457

[10] Özvan, A., Dinçer, İ., Akin, M., Oyan, V., \& Tapan, M. "Experimental studies on ignimbrite and the effect of lichens and capillarity on the deterioration of Seljuk Gravestones”. Engineering Geology, 185, pp. 81-95. 2015. https://doi.org/10.1016/j.enggeo.2014.12.001

[11] Bayraktar, A., Sevim, B., Altunişik, A. C., \& Türker, T. "Earthquake analysis of reinforced concrete minarets using ambient vibration test results”. The Structural Design of Tall and Special Buildings, 19(3), pp. 257-273. 2010. https://doi.org/10.1002/tal.464

[12] Akkaya, İ., Özvan, A., Tapan, M., \& Şengül, M. A. "Determining the site effects of 23 October 2011 earthquake (Van province, Turkey) on the rural areas using HVSR microtremor method". Journal of Earth System Science, 124(7), pp. 1429-1443. 2015. https://doi.org/10.1007/s12040015-0626-1

[13] Nakamura, Y. "A method for dynamic characteristics estimation of subsurface using microtremor on the ground surface". Quarterly Report of Railway Technical Research Institute (RTRI), 30(1), pp. 25-33. 1989.

[14] Konno, K., \& Ohmachi, T. "Ground-motion characteristics estimated from spectral ratio between horizontal and vertical components of microtremor". Bulletin of Seismological Society of America, 88(1), pp. 228-241. 1998.

[15] TEC2007 (Turkish Earthquake Resistant Code) 2007. Specification for Buildings to be Built in Seismic Zones. Turkish Ministry of Public Works and Settlement, Ankara, Turkey. http://www.koeri.boun.edu.tr/depremmuh/eski/DBYBHY2007-English-Chapters1,2.pdf

[16] Computers and Structures Inc.(CSI) SAP2000 "Linear and Nonlinear Static and Dynamic Analysis and Design of Three-Dimensional Structures". Version 14, Berkeley, CA

[17] Lourenço, P. B., Rots, J. G., \& Blaauwendraad, J. "Two approaches for the analysis of masonry structures: micro and macro-modelling”. Delft University of Technology. 1995. http://heronjournal.nl/40-4/3.pdf

[18] Altindag, R., Alyildiz, I. S., \& Onargan, T. "Mechanical property degradation of ignimbrite subjected to recurrent freeze-thaw cycles". International Journal of Rock Mechanics and Mining Sciences, 41(6), pp. 1023-1028. 2004. https://doi.org/10.1016\%2Fj.ijrmms.2004.03.005

[19] Fernandes, F., \& Lourenço, P. B. "Evaluation of the compressive strength of ancient clay bricks using microdrilling". Journal of Materials in Civil Engineering, 19(9), pp. 791-800. 2007. https://doi.org/10.1061/ (ASCE)0899-1561(2007)19:9(791) 
[20] Vermeltfoort, A. T., Martens, D. R. W., \& Van Zijl, G. P. A. G. "Brickmortar interface effects on masonry under compression". Special Issue on Masonry. Canadian Journal of Civil Engineering, 34(11), 1475-1485. 2007. https://doi.org/10.1139/L07-067

[21] Fuente, J. V., Fernandez, R., \& Albert, V. "Brick masonry elastic modulus determination using the numerical simulation and experiments of sonic wave propagation". Simulation in NDT. Online Workshop in www. ndt.net in September 2010. http://www.ndt.net/article/SimNDT2010/papers/15_Fuente.pdf

[22] Ip, F. "Compressive strength and modulus of elasticity of masonry prisms". Msc Thesis, Carleton University, Ottawa, Canada. 1999. http:// www.nlc-bnc.ca/obj/s4/f2/dsk1/tape8/PQDD_0019/MQ48451.pdf
[23] Kaushik, H. B., Rai, D. C., \& Jain, S. K. "Stress-strain characteristics of clay brick masonry under uniaxial compression". Journal of Materials in Civil Engineering, 19(9), pp. 728-739. 2007. https://doi.org/10.1061/ (ASCE)0899-1561(2007)19:9(728)

[24] Javed, M. "Seismic risk assessment of unreinforced brick masonry buildings system of northern Pakistan". Ph.D. Dissertation, N-W.F.P. University of Engineering and Technology, Peshawar, Pakistan. 2009. https://www.researchgate.net/profile/Mohammad_Javed2/publication/257943495_Seismic_Risk_Assessment_of_Unreinforced_Brick_ Masonry_Buildings_System_of_Northern_Pakistan/links/00b7d5266989475cd1000000.pdf

[25] KOERI 2016. Boğaziçi University, Kandilli Observatory and Earthquake Research Institute, Regional Earthquake-Tsunami Monitoring Center, http://www.koeri.boun.edu.tr/sismo/2/earthquake-catalog/ 